\title{
Efficacy of fuzzy MADM approach in Six Sigma analysis phase in automotive sector
}

\author{
Rajeev Rathi ${ }^{1} \cdot$ Dinesh Khanduja $^{1} \cdot$ S. K. Sharma ${ }^{1}$
}

Received: 15 December 2014/ Accepted: 20 January 2016/Published online: 12 February 2016

(C) The Author(s) 2016. This article is published with open access at Springerlink.com

\begin{abstract}
Six Sigma is a strategy for achieving process improvement and operational excellence within an organization. Decisions on critical parameter selection in analysis phase are always very crucial; it plays a primary role in successful execution of Six Sigma project and for productivity improvement in manufacturing environment and involves the imprecise, vague and uncertain information. Using a case study approach; the paper demonstrates a tactical approach for selection of critical factors of machine breakdown in center less grinding (CLG) section at an automotive industry using fuzzy logic based multi attribute decision making approach. In this context, we have considered six crucial attributes for selection of critical factors for breakdown. Mean time between failure is found to be the pivotal selection criterion in CLG section. Having calculated the weights pertinent to criteria through two methods (fuzzy VIKOR and fuzzy TOPSIS) critical factors for breakdown are prioritized. Our results are in strong agreement with the perceptions of production and maintenance department of the company.
\end{abstract}

Keywords Six Sigma - Analytical hierarchy process . Fuzzy logic $\cdot$ MADM - Center less grinding - Automotive industry

Rajeev Rathi

rajeevrathi_1443@nitkkr.ac.in

Dinesh Khanduja

dineshkhanduja@yahoo.com

S. K. Sharma

sksharma49nitk@yahoo.com

1 Department of Mechanical Engineering, National Institute of Technology, Kurukshetra, Haryana 136119, India

\section{Introduction}

Companies are continuously facing the resistance to settle into the ever changing technological environment. Six Sigma has been recognized for many years as an efficient strategy and has helped several companies to rise to this challenge. This is one of the most important and popular developments in the field of process improvement. It has saved large amounts of money and improved the processes for a large number of manufacturing organizations worldwide (Neuman and Cavanagh 2000; Snee and Hoerl 2003; Harry and Schroeder 2005). Six Sigma has gone through a considerable evolution since the early exposition. Initially it was a quality improvement methodology based on statistical concepts. Then it transformed to a disciplined process improvement technique. In its current existence; it is commonly presented as 'a breakthrough strategy' of best in class. It is accepted that in current scenario Six Sigma is applicable to various environments such as service, manufacturing, process, software industry regardless of the size of the business, and, if successfully implemented, it may lead to nearly perfect solutions and services (Banuelas et al. 2005; Antony et al. 2006; Chakrabarty and Tan 2007). Six Sigma has enormous potential to reduce breakdown costs, improve performance, grow revenue, strengthen focus, and empower resources (Snee and Hoerl 2004). It is a commanding strategy that employs a regimented approach to undertake process variability using the application of statistical and non-statistical tools and techniques in an accurate way (Jiju 2004). This teaches everyone in the organization to become more effective and efficient (Eckes 2003). Business leaders must be aware that successful implementation of Six Sigma requires not only technical understanding, but also behavioral awareness (Linderman et al. 2003). Most of the SMEs (Small and 
medium-sized enterprises) are not aware of Six Sigma and many not have the proper resources to execute Six Sigma projects (Jiju et al. 2005). In comparison with conventional approaches of quality and process improvement, Six Sigma is the most effective approach because of the interrelation between planning, organizational structures, measures, tools and techniques (Tilo et al. 2004; Zu et al. 2008). Six Sigma is a process improvement strategy which includes various phases logically related with each other acronym DMAIC methodology (define, measure, analyze, improve and control) is used for continuous improvement in any system or processes (Amer et al. 2008). It is the strategy of achieving key improvements in the process by applying DMAIC methodology through elimination of causes. Manufacturing units can put into action such strategies to enhance productivity of their manufacturing processes (Singh and Singh 2014).

In this case study, we are focusing on the analysis phase of DMAIC methodology through which all Six Sigma projects are executed. In the analysis phase, all measurements will be analyzed by understanding them and to make basic problem easier. The idea is to search for the factors having the biggest impact on process performance and determine the roots causes. In this case we have identified various factors for breakdown/failure in center less grinding section of machine shop in an automotive industry. The aim of study is to prioritize the critical breakdown factors in CLG section for further improvement. In this context, the key attributes/impacts were identified that depended on the views of various decision makers (such as machine operators, maintenance experts, production manager, technical and financial experts, etc.) and there are no crystalline themes among the views of these decision makers. Therefore it turned out to be necessary to forecast the excellent solution in terms of selecting critical factors for such problems using a decision-making technique. Such problems can be attempted with multiple attribute decision making (MADM) approach. MADM models are used to select best alternative from the large number of alternatives for a set of selection criteria. This approach has been effectively applied in broad range of decision-making problems in engineering and scientific fields (Perego and Rangone 1998; Pahlavani 2010). A variety of methods are reported under MADM category in literature (Chen et al. 1992; Tönshoff et al. 2007). MADM approach includes analytic hierarchy process (AHP) (Saaty 2014), graph theory and matrix approach (GTMA) (Rabbani et al. 2014), VlseKriterijumska Optimisacija I Kompromisno Resenje (VIKOR) (Liu et al. 2014; Singh and Kumar 2014), technique for order preference by similarity to ideal solution (TOPSIS) (Chu 2002; Chu and Lin 2003; Khanna et al. 2011; Dey et al. 2014), simple additive weighting (SAW) (Afshari et al. 2010) multiplicative analytical hierarchy process (MAHP) (Cheng and Mon 1994), weighted product method (WPM), Group decision making (GDM) (Chen 2000) and many others. These techniques have been successfully applied to various fields of engineering and among these, VIKOR and TOPSIS are outstanding multiple attribute decision making (MADM) approaches. These have been applied to various problems ranging from advanced manufacturing (Kulak and Kahraman 2005), production planning (Chen and Liao 2003), supplier selection (Azar et al. 2011), decision making (Sanayei et al. 2010), machine tool selection (Nguyen et al. 2014), supply chain management (Wei et al. 2007) and many more (Vats and Vaish 2013; Ding and Kamaruddin 2014; Tahriri et al. 2014; Tiwary et al. 2014; Vats and Vaish 2014a, b). These approaches work on crisp value of attributes/impacts. The aim of present study is to select critical factors for breakdown/failure in CLG section under fuzzy environment using fuzzy VIKOR and fuzzy TOPSIS methodology using AHP weights. The present study is one of the first efforts to evaluate failure parameters using fuzzy MADM approach in Six Sigma analysis phase in Indian automotive sector.

\section{Evaluation criteria}

Six attributes have been identified for evaluation of the critical breakdown factors in center less grinding section of the selected automotive industry. These are based on the discussion with various technical experts, machine operators, production manager, maintenance manager and studies conducted by various researchers (Ayă $\breve{g}$ and Özdemir 2011; Nguyen et al. 2014).

\begin{tabular}{|c|c|c|}
\hline $\begin{array}{l}\text { Attributes/ } \\
\text { impact }\end{array}$ & Symbol & Depiction \\
\hline $\begin{array}{l}\text { Ease of } \\
\text { maintenance }\end{array}$ & $C_{1}$ & $\begin{array}{l}\text { It describes the ease with which a machine } \\
\text { can be maintained in order to correct } \\
\text { defects or their causes. Ease of } \\
\text { Maintenance is the means whereby the } \\
\text { Project Team confirms whether } \\
\text { equipment can be maintained in-service } \\
\text { and meets the maintainability and ease } \\
\text { of maintenance criteria within the } \\
\text { maintenance strategy }\end{array}$ \\
\hline Safety & $C_{2}$ & $\begin{array}{l}\text { There are common hazards associated } \\
\text { with the use of machine shop equipment } \\
\text { and tools. Working safely is the first } \\
\text { thing because the safe way is the correct } \\
\text { way. The costs of accidents and ill health } \\
\text { to engineering machine shops may be } \\
\text { disproportionately high. Many } \\
\text { employees are 'key' workers whose } \\
\text { losses through injury or ill health } \\
\text { severely disrupt production and lowers } \\
\text { productivity and profitability }\end{array}$ \\
\hline
\end{tabular}


continued

Attributes/ Symbol Depiction

impact

\begin{tabular}{cc}
\hline MTBF & It is the prime factor for selecting critical \\
& reasons of breakdown in machine shops. \\
& MTBF is stated as the average time \\
& between system failures of the entire \\
& machine shop. It defines of how reliable \\
& a component is. It shows the failure rate \\
& of each parameter responsible for \\
& breakdown in CLG section \\
& It is also a key factor for investigating \\
& critical reasons of breakdown. It includes \\
& the cost of breakdown, maintenance, \\
& repair and all activities necessary to \\
& meet all its functional requirements \\
& throughout the service life. This \\
& becomes a critical to estimate such costs \\
& Green Effects go beyond just energy \\
& efficiency and attempt to rate an effort \\
& with regard to the total environmental \\
& stewardship of a machine shop. It \\
& includes minimum wastage, low energy \\
& consumption and user friendly \\
Green effect & environment. In this regard green effects \\
& are significantly more encompassing \\
& than just energy. An energy efficient \\
& shop floor may not be a green shop floor, \\
& but a true shop floor will be energy \\
& efficient
\end{tabular}

Repair time $\quad C_{6} \quad$ It is the Portion of breakdown time during which one or more experts are working on a system to effect a repair. Repair time includes preparation time, fault detection time, fault correction time and final bind up time

\section{Methods}

As discussed in previous section, the present study emphasizes on finding out critical factors responsible for breakdown time in CLG's to improve their availability and to enhance company profit. This is done by first optimizing the parameters using AHP and then using VIKOR and TOPSIS with fuzzy logic to sum up the result.

\section{Analytical hierarchy process (AHP)}

Analytic hierarchy process is a decision making model that aids us in making decision in our complex world, developed by Satty $(1980,1988)$. AHP provides a framework to cope with multiple criteria situations involving intuitive, rational, qualitative and quantitative aspects. It has been one of the most widely used techniques for complex decision found especially suitable for planning at strategic level. It is a three part process which includes, identifying and organizing decision objectives, criteria constraints and alternatives into a

hierarchy. The process requires the decision-maker to develop a hierarchical structure of the factors in the given problem and to provide judgments about the relative importance of each of these factors and ultimately to specify a preference for each decision alternative with respect to each factor (Bhutta and Huq 2002). The elements of the hierarchy are related to an aspect of the decision problem which can be carefully measured or roughly estimated anything at all that applies to the decision making. Generally hierarchy has three levels; the goal, the criteria, the alternatives. The levels of hierarchy describe a system from the lowest level (sets of alternatives), through the intermediate levels (sub criteria and criteria), to the highest level (general object) (Liu and Hai 2005). It is the essence of the AHP that human judgments, and not just the underlying information, can be used in performing the evaluations. In order to compare distinct attributes, numeric priority values are assigned to the attributes on the scale of 1-9 (Saaty 1990). AHP is used as a framework to formulize the evaluation of trade-offs between the conflicting selections criteria associated with the various suppliers' offers (Nydick and Hill 1992; Radcliffe and Schniederjans 2003). The comparison is based on expert opinion, some inconsistency may occur in the system. The consistency of system can be checked by the consistency ratio $(\mathrm{CR})$ :

$\mathrm{CR}=\frac{\mathrm{CI}}{\mathrm{RI}}$

where $\mathrm{CI}$ is the consistency index which can be written as:

$C I=\frac{\lambda_{\max }-m}{m-1}$

The random consistency index (R.I.) is the predefined value (Satty 1994).

\section{Fuzzy logic}

Fuzzy approach was introduced to undertake the problem where there are no clear edges between the two parameters (Azar et al. 2011). It deals with the problems where it is hard to differentiate between members and non-member objects of a set. Fuzzy approach was used for multiple criteria decision making where the stress is on likelihood rather than probability (Wei et al. 2007). Fuzzy logic is based on a set theory and contains a membership function within the interval $(0,1)$ which depicts the extent of significance of an element for being the member of the set (Bevilacqua et al. 2006). Linguistic variables are used for all the assessments, in which numerical values are assigned without any riddle. A linguistic variable is a variable whose value is denoted in words or sentences in a natural or artificial language (Zadeh 1975). For example, if the values of quality are presumed to be the fuzzy variables marked as good, bad and worst in place of actual numbers, then 


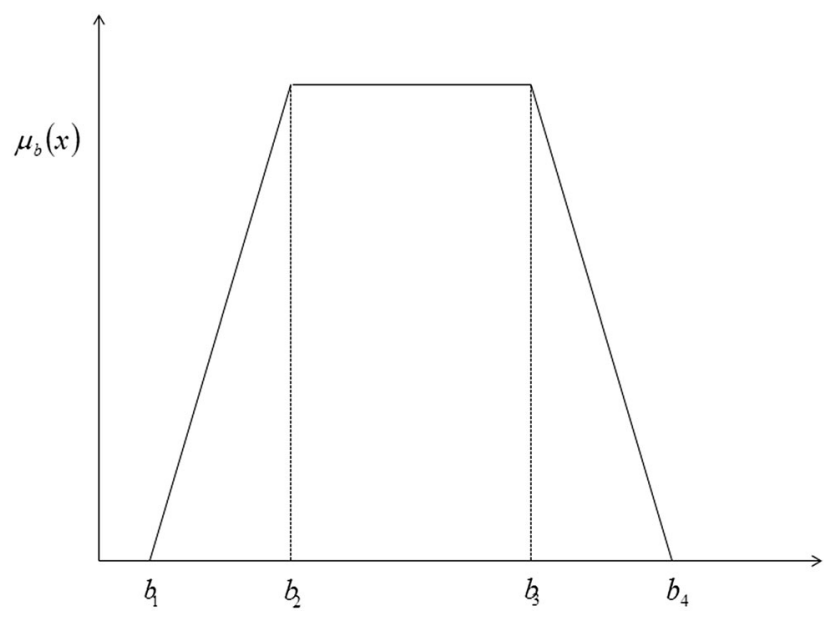

Fig. 1 Trapezoidal fuzzy number

quality is a linguistic variable. Fields of artificial intelligence, linguistics, pattern recognition, human decision processes, psychology, economics etc. have origin in the linguistic approach (Bellman and Zadeh 1970). Different fuzzy numbers are used depending on their situation. In present case we use trapezoidal fuzzy numbers $\left(b_{1}, b_{2}, b_{3}\right.$, $b_{4}$ ) for $\left\{b_{1}, b_{2}, b_{3}, b_{4} \in R ; b_{1} \leq b_{2} \leq b_{3} \leq b_{4}\right\}$ as in Fig. 1. Because of its simplicity and information processing in a fuzzy environment; it is often suitable to work with trapezoidal fuzzy numbers. The membership function $\mu_{b}(x)$ of trapezoidal fuzzy number is defined as

$\mu_{b}(x)= \begin{cases}\frac{x-b_{1}}{b_{2}-b_{1}}, & x \in\left[b_{1}, b_{2}\right] \\ 1, & x \in\left[b_{2}, b_{3}\right] \\ \frac{b_{4}-x}{b_{4}-b_{3}}, & x \in\left[b_{3}, b_{4}\right] \\ 0, & \text { otherwise }\end{cases}$

\section{VIKOR}

Opricovic (2011) developed VIKOR, the Serbian name: VlseKriterijumska Optimizacija I Kompromisno Resenje; method to determine the compromise solution for a set of alternatives. Compromise solution is a feasible solution closest to the ideal solution for a MADM problem. The compromise solutions could be the basis for agreements, involving the decision maker's preferences by criteria weight. This method focuses on ranking and selecting from a set of alternatives, and determines compromise solutions for a problem with conflicting criteria, which can help the decision makers to reach a final decision (Sanayei et al.
2010). VIKOR algorithm determines the weight stability intervals for the obtained compromise solution with the input weights given by the experts.

\section{TOPSIS}

TOPSIS (Technique for order preference by similarity to an ideal solution) method was presented by Hwang and Yoon (Yoon and Hwang 1995). TOPSIS uses different weighting schemes and distance metrics to compares results of different sets of weights applied to set of multiple criteria data (Olson 2004; Önüt and Soner 2008). The basic principle is that the chosen alternative should have the shortest distance from the ideal solution and the farthest distance from the negative ideal solution. The ideal solution is a solution that maximizes the benefit criteria and minimizes the cost criteria, whereas the negative ideal solution maximizes the cost criteria and minimizes the benefit criteria. Benefit criteria is for maximization, while the cost criteria is for minimization. The best alternative is the one, which is closest to the ideal solution and farthest from the negative ideal solution (Wang and Elhag 2006).

\section{Methodology used}

This section explains the steps involved in the proposed subjective fuzzy VIKOR and Fuzzy TOPSIS approach for calculation of critical factors responsible for breakdown in CLG's. The approach utilizes AHP weights for intercomparison among all criteria followed by fuzzy logic approach with VIKOR and TOPSIS methods. Figure 2 shows the flow chart of proposed methodology used in present study and make clears how the views of the decision makers are quantitatively compiled. It includes following steps:

Step 1 Calculation of AHP weights.

As discussed in "Analytical hierarchy process (AHP)" section, AHP weights $\left(W_{j}\right)$ are calculated for all breakdown parameters. This provides the weights of different criteria.

Step 2 Define linguistic terms, relevant membership function and corresponding fuzzy numbers. A set of fuzzy rates is required in order to compare all the alternatives for each criterion. These fuzzy terms are assigned by the decision makers and responsible for intra criterion comparisons of the alternatives. 
Step 3 Decision matrix formation.

Let $p$ be the parameters and $q$ be the alternative. For $k$ number of decision makers in the proposed model for the aggregated fuzzy rating for $C_{j}$ criterion is represented as $x_{i j k}=\left\{x_{i j k 1}, x_{i j k 2}, x_{i j k 3}\right.$, $\left.x_{i j k 4}\right\}$. For $i=1,2, \ldots p ; j=1,2, \ldots q ; k=1,2, \ldots$ $k, x_{i j k}$ is calculated as (Kahraman et al. 2003; Kwong and Bai 2003):

$$
\left\{\begin{array}{l}
x_{i j 1}=\min _{k}\left\{b_{i j k 1}\right\} \\
x_{i j 2}=\frac{1}{k} \sum b_{i j k 2} \\
x_{i j 3}=\frac{1}{k} \sum b_{i j k 3} \\
x_{i j 4}=\max _{k}\left\{b_{i j k 4}\right\}
\end{array}\right.
$$

Thus the obtained decision matrix $(M)$ is shown as:

$$
M=\left[\begin{array}{llll}
x_{11} & x_{12} & \cdots & x_{1 p} \\
x_{21} & x_{22} & \cdots & x_{2 p} \\
\vdots & \vdots & \ddots & \vdots \\
\vdots & \vdots & \ddots & \vdots \\
x_{q 1} & x_{q 2} & \cdots & x_{q p}
\end{array}\right]
$$

\section{Step 4 Defuzzification.}

Defuzzification is performed to obtain the crisp values for each criterion corresponding to each alternative. This provides a quantitative value for the linguistic variables and fuzzy numbers assigned based on the verbal reasoning of the decision makers. Following equation lead to the crisp values:
The crisp values, thus obtained are integrated with AHP weights to calculate final ranking usingVIKOR and TOPSIS approach as discussed below.

\section{VIKOR approach steps}

Step 5 Determination of ideal and negative ideal solutions;

The ideal solution $f^{*}$ and negative ideal solution $f^{-}$are determined as

$$
\begin{aligned}
& f^{*}=\left\{\max f_{i j}\right\} \\
& f^{-}=\left\{\min f_{i j}\right\}
\end{aligned}
$$

Step 6 Calculation of utility and regret measures

$$
\begin{aligned}
& S_{i}=\sum_{j=1}^{n} W_{j} \frac{\left(f_{j}^{*}-f_{i j}\right)}{\left(f_{j}^{*}-f_{j}^{-}\right)} ; \quad \forall i \\
& R_{i}=\operatorname{Max}_{j}\left[W_{j} \frac{\left(f_{j}^{*}-f_{i j}\right)}{\left(f_{j}^{*}-f_{j}^{-}\right)}\right] ; \quad \forall i
\end{aligned}
$$

where $\mathrm{S}_{i}$ and $\mathrm{R}_{i}$ represent the utility and regret measures, respectively and $W_{j}$ is the relative weight assigned to the $j$ th parameter using AHP.

$$
\begin{aligned}
f_{i j} & =\operatorname{Defuzz}\left(x_{i j}\right)=\frac{\int \mu(x) \cdot x \mathrm{~d} x}{\int \mu(x) \cdot \mathrm{d} x} \\
& =\frac{\int_{x_{i j 1}}^{x_{i j 2}}\left\{\left(x-x_{i j 1}\right) /\left(x_{i j 2}-x_{i j 1}\right)\right\} \cdot x \mathrm{~d} x+\int_{x i j 2}^{x_{i j 3}} x \mathrm{~d} x+\int_{x_{i j 3}}^{x_{i j 4}}\left\{\left(x_{i j 4}-x\right) /\left(x_{i j 4}-x_{i j 3}\right)\right\} \cdot x \mathrm{~d} x}{\int_{x_{i j 1}}^{x_{i j}}\left\{\left(x-x_{i j 1}\right) /\left(x_{i j 2}-x_{i j 1}\right)\right\} \mathrm{d} x+\int_{x i j 2}^{x_{i j 3}} \mathrm{~d} x+\int_{x_{i j 3}}^{x_{i j 4}}\left\{\left(x_{i j 4}-x\right) /\left(x_{i j 4}-x_{i j 3}\right)\right\} \cdot x \mathrm{~d} x} \\
& =\frac{-x_{i j 1} x_{i j 2}+x_{i j 3} x_{i j 4}+(1 / 3)\left(x_{i j 4}-x_{i j 3}\right)^{2}+(1 / 3)\left(x_{i j 2}-x_{i j 1}\right)^{2}}{-x_{i j 1}-x_{i j 2}-x_{i j 3}+x_{i j 4}}
\end{aligned}
$$




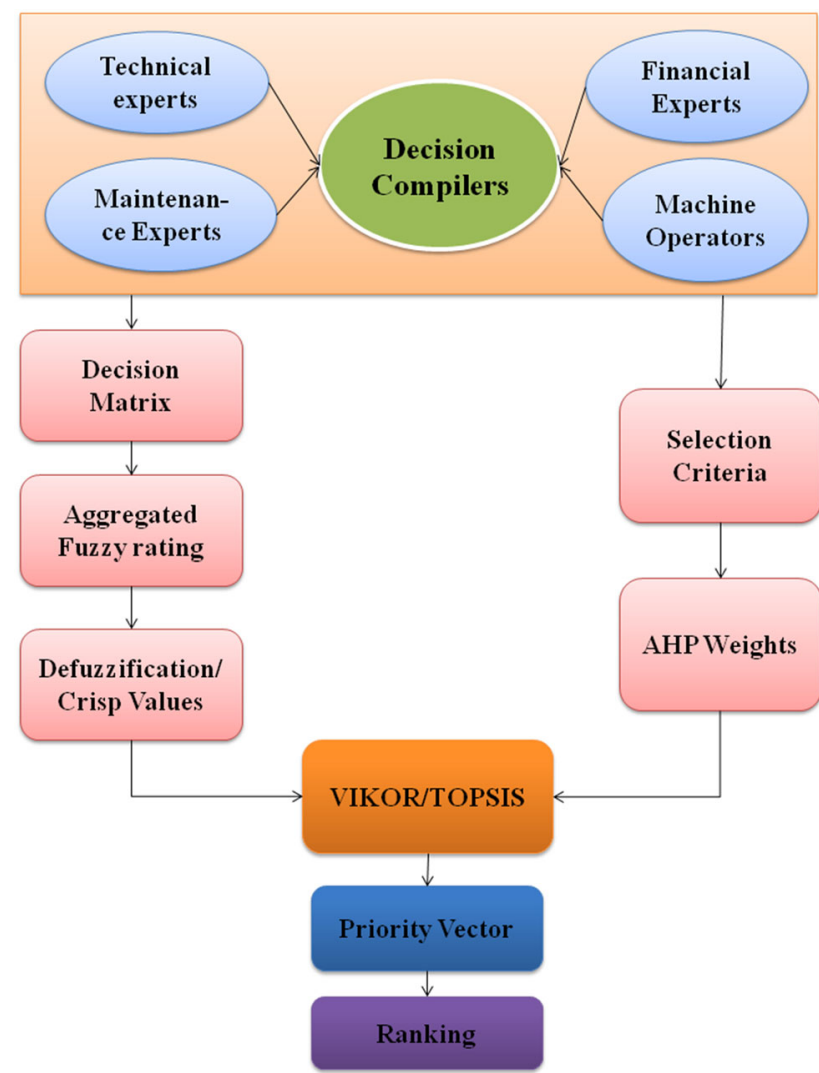

Fig. 2 Flow chart for methodology used

Step 7 Calculation of VIKOR index

$Q_{i}=v\left[\frac{S_{i}-S^{*}}{S^{-}-S^{*}}\right]+(1-v)\left[\frac{R_{i}-R^{*}}{R^{-}-R^{*}}\right] ; \quad \forall i$

where $Q_{i}$ represents $i$ th alternatives VIKOR value, $v$ is the group utility weight, it is generally considered as 0.5 (unsupervised) and;

$S^{*}=\min _{i}\left(S_{i}\right)$

$S^{-}=\max _{i}\left(S_{i}\right)$

$R^{*}=\min _{i}\left(R_{i}\right)$

$R^{-}=\max _{i}\left(R_{i}\right)$

Breakdown factor with least value of VIKOR index $Q_{i}$ is preferred.

\section{TOPSIS approach steps}

Step 5 Normalized the matrix as given below:

$$
r_{i j}=\frac{f_{i j}}{\sqrt{\sum_{i=1}^{m}\left(f_{i j}\right)^{2}}} ; \quad \forall_{j}
$$

Step 6 Calculate the weighted normalized decision matrix as given:

$V_{i j}=\left[r_{i j}\right]_{m \times n} \times\left[W_{j}\right]_{n \times m}^{\text {diagonal }}$

Step 7 Calculate the positive ideal and negative ideal solution:

The positive ideal solution $V_{j}^{+}$and negative ideal solution $V_{j}^{-}$are as given below:

$$
\begin{gathered}
V_{j}^{+}=\left\{\left(\max V_{i j}, j \in J_{1}\right),\left(\min V_{i j}, j \in J_{2}\right),\right. \\
\quad i=1,2,3 \ldots m\} ; \quad \forall j \\
V_{j}^{-}=\left\{\left(\min V_{i j}, j \in J_{1}\right),\left(\max V_{i j}, j \in J_{2}\right),\right. \\
i=1,2,3 \ldots m\} ; \quad \forall j
\end{gathered}
$$

where $J_{1}$ and $J_{2}$ represents higher best and lower best criteria respectively.

Step 8 Calculate the distance $d_{i}^{+}$and $d_{i}^{-}$from the positive ideal solution and negative ideal solution respectively

$$
\begin{gathered}
d_{i}^{+}=\left[\sum_{j=1}^{n}\left(V_{i j}-V_{j}^{+}\right)^{2}\right]^{0.5}, \\
i=1,2,3, \ldots m \\
d_{i}^{-}=\left[\sum_{j=1}^{n}\left(V_{i j}-V_{j}^{-}\right)^{2}\right]^{0.5}, \\
i=1,2,3, \ldots m
\end{gathered}
$$

Step 9 Calculation of TOPSIS rank index:

$$
C_{i}^{+}=\frac{d_{i}^{-}}{d_{i}^{-}+d_{i}^{+}}
$$

Breakdown factor with highest rank index $C_{i}^{+}$are preferred. 

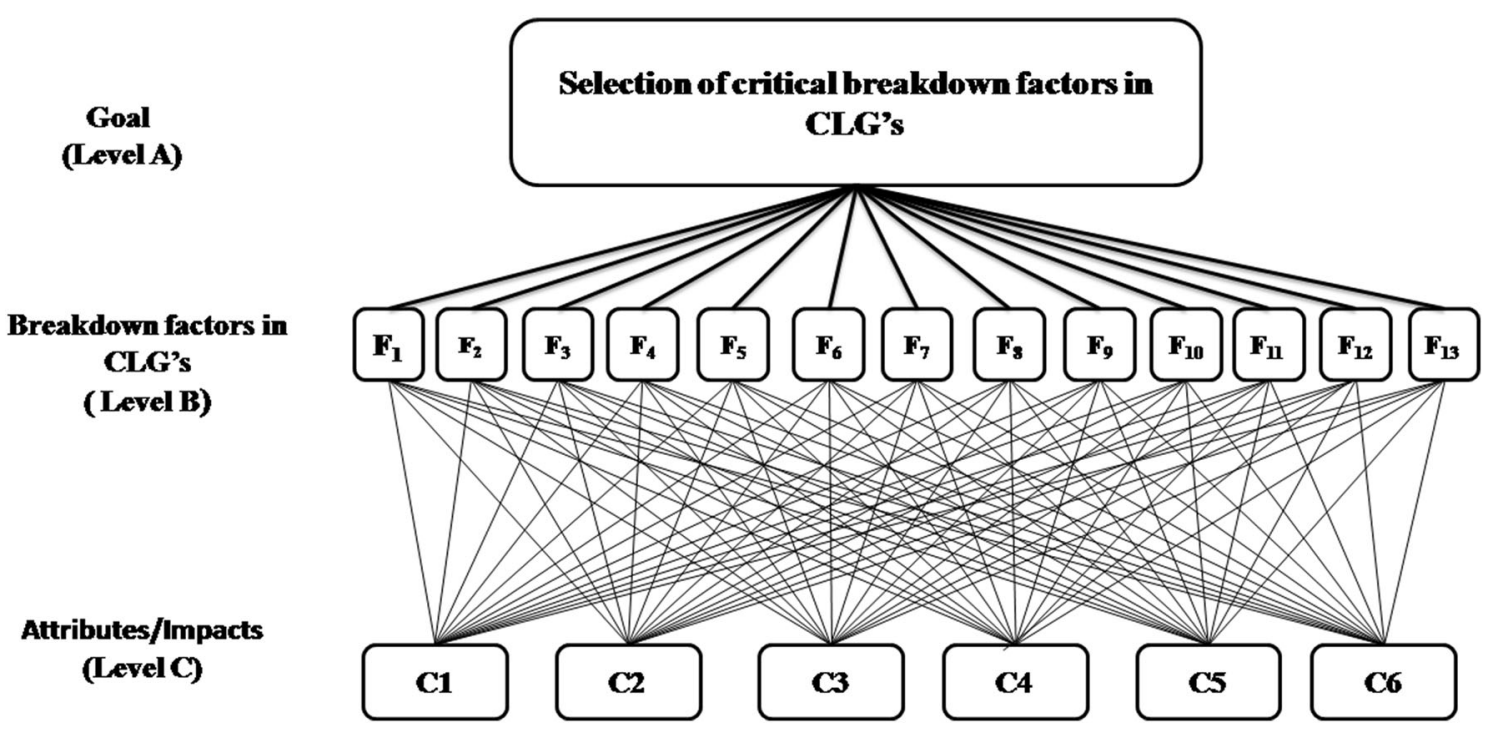

Fig. 3 The hierarchical structure for the selection of the critical factors of Breakdowns in CLG's

Table 1 Subjective weights of the evaluation criteria calculated using AHP

\begin{tabular}{lllllllll}
\hline Attributes/impact & $C_{1}$ & $C_{2}$ & $C_{3}$ & $C_{4}$ & $C_{5}$ & $C_{6}$ & Weights & Rank \\
\hline Ease of maintenance $\left(C_{1}\right)$ & 1 & 5 & 0.11 & 0.14 & 5 & 0.14 & 0.0768 & 4 \\
Safety $\left(C_{2}\right)$ & 0.20 & 1 & 0.11 & 0.14 & 3 & 0.14 & 0.0381 & 5 \\
MTBF $\left(C_{3}\right)$ & 9 & 9 & 1 & 9 & 9 & 9 & 0.4945 & 1 \\
Cost $\left(C_{4}\right)$ & 7 & 7 & 0.11 & 1 & 7 & 7 & 0.2187 & 2 \\
Green effect $\left(C_{5}\right)$ & 0.20 & 0.33 & 0.11 & 0.14 & 1 & 0.14 & 0.0239 & 6 \\
Repair time $\left(C_{6}\right)$ & 7 & 7 & 0.11 & 0.14 & 7 & 1 & 0.1478 & 3 \\
\hline
\end{tabular}

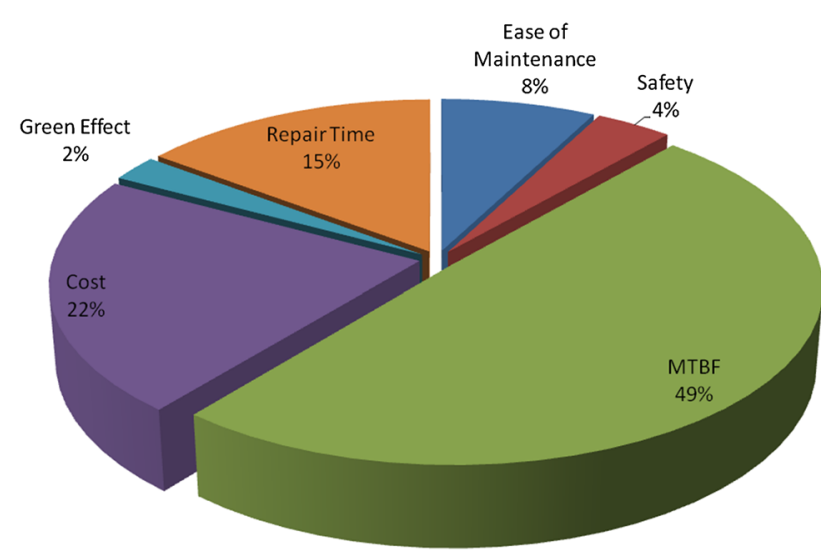

Fig. 4 Contribution of all dominating attributes about selection of critical factors for breakdown in CLG's

\section{Results and discussion}

The hierarchical structure for the selection of critical breakdowns factors in CLG's is demonstrated in Fig. 3. Level A specifies our goal on selection of the critical factors that have to be selected from the identified thirteen important factors of failure indicated in level B. Further, in
Table 2 Linguistic variables and corresponding fuzzy numbers

\begin{tabular}{ll}
\hline Linguistic variable & Fuzzy number \\
\hline Absolutely high (AH) & $(0.8,0.9,1.0,1.0)$ \\
Very high (VH) & $(0.7,0.8,0.8,0.9)$ \\
High (H) & $(0.5,0.6,0.7,0.8)$ \\
Above average (AA) & $(0.4,0.5,0.5,0.6)$ \\
Below average (BA) & $(0.2,0.3,0.4,0.5)$ \\
Very poor (VP) & $(0.1,0.2,0.2,0.3)$ \\
Absolutely poor (AP) & $(0.0,0.0,0.1,0.2)$ \\
\hline
\end{tabular}

brainstorming session with decision makers like machine operators, maintenance experts, production manager, technical and financial experts etc.; we concluded that selection of the critical factors of breakdowns in CLG's depends on six criteria as discussed in "Evaluation criteria" section and these are illustrated in level C of the Fig. 3 as attributes/impacts. Breakdown parameters are fully interdependent on these attributes and it shows the intricacy of the problem. Moreover, this is a time consuming process and significant knowledge of both technological as well as economic aspects is needed in this case. After the 


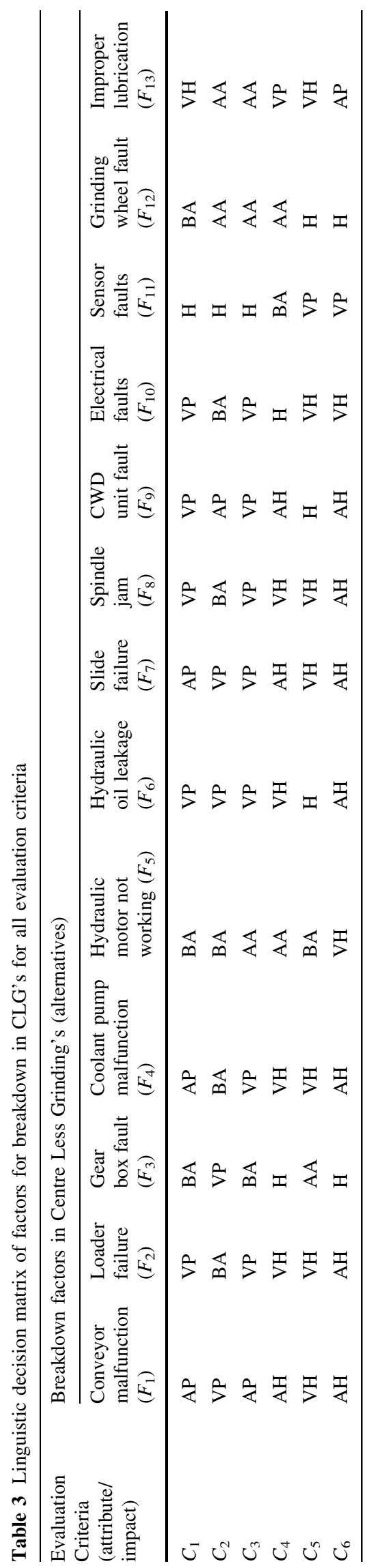

attributes are identified, the next issue is to prioritize these attributes, as to which one has more impact on the identified breakdown reasons. AHP approach is used to prioritize these attributes and in order to compare these distinct attributes, numeric priority values are assigned to the attributes on a scale of 1-9 and pair-wise comparison is made. Table 1 shows the relative decision matrix formed on the basis of pair-wise comparison (AHP approach) and the weights calculated for all the considered criteria. MTBF appease as the most dominant attribute for the selection of these critical reasons of breakdown; while green effect is found to be the least dominant factor. Figure 4 shows contribution of all these dominating attributes towards selection of these critical breakdown factors. It is clearly observed that contributions of these attributes vary from shop floor of company to company.

In next step, fuzzy hypothesis analysis is performed on conclusions of the decision makers for comparison of all alternatives for each attribute. Fuzzy logic approach dealt well with such problems. Linguistic variables were used for selection of the critical factors of breakdowns. These were further converted into fuzzy numbers as shown in Table 2 for the current study. The highest range is termed absolutely high (AH) and the least is termed as absolutely poor (AP). Table 3 demonstrates the linguistic decision matrix filled during brainstorming session with decision makers. Here a single decision matrix has been formed rather than having a separate decision matrix for each decision maker. However, it is clearly known that final decision matrix can change as per the requirements and existing conditions. Further, fuzzy values are finally transformed into crisp values as shown in Eq. (5). Table 4 shows the calculated crisp values obtained from aggregated fuzzy ratings. Calculated crisp values are used with VIKOR approach as shown in Eqs. (6)-(14) and these values are used with TOPSIS approach, using Eqs. (15)-(21) to obtain the rank indices of all alternatives. Table 5 shows corresponding rank indices and ranks for the factors of breakdowns in CLG's. The ranking of alternatives obtained by VIKOR and TOPSIS approach are exactly same. This shows the robustness of the results used. Our computation shows that conveyor malfunction is the prime factor for breakdown in CLG section. Other main reasons for breakdown are slide failure, CWD unit fault, coolant pump malfunction and hydraulic oil leakage, respectively (refer Table 5). It is also observed that sensor faults are having least effect on failure of this section. Improper lubrication and grinding wheel fault and electrical faults are also rarely responsible for failure. We found that our results are in good agreement with long term perceptions of auto companies under normal working conditions. These critical causes of capacity waste need immediate monitoring, so that productivity loss could be checked for future. 
Table 4 Calculated crisp values for assigned fuzzy rates

\begin{tabular}{lllllllllllllll}
\hline Evaluation criteria & \multicolumn{1}{l}{ Breakdown factors in CLG's (alternatives) } \\
\cline { 2 - 15 } & $F_{1}$ & $F_{2}$ & $F_{3}$ & $F_{4}$ & $F_{5}$ & $F_{6}$ & $F_{7}$ & $F_{8}$ & $F_{9}$ & $F_{10}$ & $F_{11}$ & $F_{12}$ & $F_{13}$ \\
\hline$C_{1}$ & 0.0778 & 0.2333 & 0.3667 & 0.0778 & 0.3667 & 0.2333 & 0.0778 & 0.2333 & 0.2333 & 0.2333 & 0.6667 & 0.3667 & 0.8333 \\
$C_{2}$ & 0.3833 & 0.3667 & 0.2333 & 0.3667 & 0.3667 & 0.2333 & 0.2333 & 0.3667 & 0.0778 & 0.3667 & 0.6667 & 0.5333 & 0.5333 \\
$C_{3}$ & 0.1778 & 0.2333 & 0.3667 & 0.2333 & 0.5333 & 0.2333 & 0.2333 & 0.2333 & 0.2333 & 0.2333 & 0.6667 & 0.5333 & 0.5333 \\
$C_{4}$ & 0.9444 & 0.8333 & 0.6667 & 0.8333 & 0.5333 & 0.8333 & 0.9444 & 0.8333 & 0.9444 & 0.6667 & 0.3667 & 0.5333 & 0.2333 \\
$C_{5}$ & 0.9833 & 0.8333 & 0.5333 & 0.8333 & 0.3667 & 0.6667 & 0.8333 & 0.8333 & 0.6667 & 0.8333 & 0.2333 & 0.6667 & 0.8333 \\
$C_{6}$ & 0.9444 & 0.9444 & 0.6667 & 0.9444 & 0.8333 & 0.9444 & 0.9444 & 0.9444 & 0.9444 & 0.8333 & 0.2333 & 0.6667 & 0.0778 \\
\hline
\end{tabular}

Table 5 Calculated VIKOR and TOPSIS ranking

\begin{tabular}{|c|c|c|c|c|c|c|c|c|c|c|c|c|c|}
\hline \multirow[t]{2}{*}{ Evaluation criteria } & \multicolumn{13}{|c|}{ Breakdown factors in CLG's (alternatives) } \\
\hline & $F_{1}$ & $F_{2}$ & $F_{3}$ & $F_{4}$ & $F_{5}$ & $F_{6}$ & $F_{7}$ & $F_{8}$ & $F_{9}$ & $F_{10}$ & $F_{11}$ & $F_{12}$ & $F_{13}$ \\
\hline VIKOR rank index & 0 & 0.09 & 0.297 & 0.08 & 0.485 & 0.088 & 0.054 & 0.09 & 0.061 & 0.133 & 0.75 & 0.503 & 0.648 \\
\hline VIKOR ranks & 1 & 7 & 9 & 4 & 10 & 5 & 2 & 6 & 3 & 8 & 13 & 11 & 12 \\
\hline TOPSIS ranks & 1 & 7 & 9 & 4 & 10 & 5 & 2 & 6 & 3 & 8 & 13 & 11 & 12 \\
\hline TOPSIS rank index & 0.9987 & 0.9806 & 0.7315 & 0.9825 & 0.3599 & 0.9811 & 0.9912 & 0.9806 & 0.9894 & 0.9333 & 0.0172 & 0.2982 & 0.0574 \\
\hline
\end{tabular}

\section{Conclusions}

Fuzzy MADM method has been used for the selection of the critical factors of breakdown in CLG section of an automotive industry. Analytical Hierarchy Process (AHP) method is used to calculate weights of all persuasive attributes for selection of the failure parameters. MTBF has been found to be the most serious and green effect as least critical attribute. Further priority order of critical breakdown factors in CLG's is determined using fuzzy VIKOR and fuzzy TOPSIS approach with AHP weights. Conveyor malfunction, slide not working, and CWD unit fault, coolant pump malfunction and hydraulic oil leakage are found to be the critical factors of breakdowns in CLG section. This study explores the feasibility of fuzzy VIKOR and fuzzy TOPSIS methods in Six Sigma analysis phase for selection of the breakdown/failure parameters. Briefly, the main features of this study are summarized as follows:

(a) The study helps to highlight the importance of 'Analysis Phase' for successful implementation of Six Sigma project.

(b) The study has also helped to prove that FuzzyMADM approach can be effectively used to select most critical CTQs, which can be further improved to achieve better sigma rating.

(c) Within MADM, the study has successfully explored the efficacy of AHP, VIKOR and TOPSIS methods to prioritize the CTQs which are highly important for execution of Six Sigma project.

(d) The study will help the managers and practitioners to implement Six Sigma more effectively and more scientifically, using MADM approaches instead of using conventional statistical tools.

Authors' contribution All authors made substantial contribution to conception or design of the work, data collection, data analysis and interpretation, drafting the article, critical revision of the article and final approval of the version to be published.

Open Access This article is distributed under the terms of the Creative Commons Attribution 4.0 International License (http://crea tivecommons.org/licenses/by/4.0/), which permits unrestricted use, distribution, and reproduction in any medium, provided you give appropriate credit to the original author(s) and the source, provide a link to the Creative Commons license, and indicate if changes were made.

\section{References}

Afshari A, Mojahed M et al (2010) Simple additive weighting approach to personnel selection problem. Int J Innov Manag Technol 1(5):511-515

Amer Y, Luong L et al (2008) Optimizing order fulfillment using design for six sigma and fuzzy logic. Int J Manag Sci Eng Manag 3(2):83-99

Antony J, Kumar A et al (2006) World class applications of six sigma. Routledge, London 
Ayağ Z, Özdemir RG (2011) An intelligent approach to machine tool selection through fuzzy analytic network process. J Intell Manuf 22(2): 163-177

Azar A, Olfat L et al (2011) A BSC method for supplier selection strategy using TOPSIS and VIKOR: a case study of part maker industry. Manag Sci Lett 1(4):559-568

Banuelas R, Antony J et al (2005) An application of Six Sigma to reduce waste. Qual Reliab Eng Int 21(6):553-570

Bellman RE, Zadeh LA (1970) Decision-making in a fuzzy environment. Manag Sci 17(4):B-141-B-164

Bevilacqua M, Ciarapica F et al (2006) A fuzzy-QFD approach to supplier selection. J Purch Supply Manag 12(1):14-27

Bhutta KS, Huq F (2002) Supplier selection problem: a comparison of the total cost of ownership and analytic hierarchy process approaches. Supply Chain Manag Int J 7(3):126-135

Chakrabarty A, Tan KC (2007) The current state of six sigma application in services. Manag Serv Qual 17(2):194-208

Chen C-T (2000) Extensions of the TOPSIS for group decisionmaking under fuzzy environment. Fuzzy Sets Syst 114(1):1-9

Chen Y-K, Liao H-C (2003) An investigation on selection of simplified aggregate production planning strategies using MADM approaches. Int J Prod Res 41(14):3359-3374

Chen SJ, Hwang CL, Hwang FP (1992) Fuzzy multiple attribute decision making: methods and applications. Springer, New York, NY

Cheng C-H, Mon D-L (1994) Evaluating weapon system by analytical hierarchy process based on fuzzy scales. Fuzzy Sets Syst 63(1): $1-10$

Chu T-C (2002) Selecting plant location via a fuzzy TOPSIS approach. Int J Adv Manuf Technol 20(11):859-864

Chu T-C, Lin Y-C (2003) A fuzzy TOPSIS method for robot selection. Int J Adv Manuf Technol 21(4):284-290

Dey PP, Pramanik S, et al (2014) TOPSIS approach to linear fractional bi-level MODM problem based on fuzzy goal programming. J Ind Eng Int 10(4):173-184

Ding S-H, Kamaruddin S (2015) Assessment of distance-based multiattribute group decision-making methods from a maintenance strategy perspective. J Ind Eng Int 11:73-85

Eckes G (2003) Six Sigma for everyone. Wiley, New York

Harry M, Schroeder R (2005) Six Sigma: the breakthrough management strategy revolutionizing the world's top corporations. Random House, LLC, New York

Jiju A (2004) Some pros and cons of six sigma: an academic perspective. TQM Mag 16(4):303-306

Jiju A, Maneesh K et al (2005) Six sigma in small- and medium-sized UK manufacturing enterprises. Int J Qual Reliab Manag 22(8):860-874

Kahraman C, Cebeci U et al (2003) Multi-criteria supplier selection using fuzzy AHP. Logist Inf Manag 16(6):382-394

Khanna HK, Sharma D et al (2011) Identifying and ranking critical success factors for implementation of total quality management in the Indian manufacturing industry using TOPSIS. Asian J Qual 12(1):124-138

Kulak O, Kahraman C (2005) Multi-attribute comparison of advanced manufacturing systems using fuzzy vs. crisp axiomatic design approach. Int J Prod Econ 95(3):415-424

Kwong C, Bai H (2003) Determining the importance weights for the customer requirements in QFD using a fuzzy AHP with an extent analysis approach. IIE Trans 35(7):619-626

Linderman K, Schroeder RG et al (2003) Six Sigma: a goal-theoretic perspective. J Oper Manag 21(2):193-203

Liu F-HF, Hai HL (2005) The voting analytic hierarchy process method for selecting supplier. Int J Prod Econ 97(3):308-317

Liu H-C, You J-X et al (2014) Site selection in waste management by the VIKOR method using linguistic assessment. Appl Soft Comput 21:453-461
Neuman RP, Cavanagh R (2000) The six sigma way: how GE, Motorola, and other top companies are honing their performance. McGraw-Hill, New York

Nguyen H-T, Dawal SZM et al (2014) A hybrid approach for fuzzy multi-attribute decision making in machine tool selection with consideration of the interactions of attributes. Expert Syst Appl 41(6):3078-3090

Nydick RL, Hill RP (1992) Using the analytic hierarchy process to structure the supplier selection procedure. J Supply Chain Manag 28(2):31

Olson DL (2004) Comparison of weights in TOPSIS models. Math Comput Model 40(7-8):721-727

Önüt S, Soner S (2008) Transshipment site selection using the AHP and TOPSIS approaches under fuzzy environment. Waste Manag 28(9):1552-1559

Opricovic S (2011) Fuzzy VIKOR with an application to water resources planning. Expert Syst Appl 38(10):12983-12990

Pahlavani A (2010) A new fuzzy MADM approach and its application to project selection problem. Int $\mathrm{J}$ Comput Intell Syst 3(1):103-114

Perego A, Rangone A (1998) A reference framework for the application of MADM fuzzy techniques to selecting AMTS. Int J Prod Res 36(2):437-458

Rabbani M, Monshi M, et al. (2014) A new AATP model with considering supply chain lead-times and resources and scheduling of the orders in flowshop production systems: a graphtheoretic view. Appl Math Model 38(24):6098-6107

Radcliffe LL, Schniederjans MJ (2003) Trust evaluation: an AHP and multi-objective programming approach. Manag Decis 41(6):587-595

Saaty TL (1988) What is the analytic hierarchy process?. Springer, New York

Saaty TL (1990) How to make a decision: the analytic hierarchy process. Eur J Oper Res 48(1):9-26

Saaty TL (2014) The analytic hierarchy process without the theory of Oskar Perron. Int J Anal Hierarchy Process 5(2). doi:10.13033/ ijahp.v5i2.191

Sanayei A, Farid Mousavi S et al (2010) Group decision making process for supplier selection with VIKOR under fuzzy environment. Expert Syst Appl 37(1):24-30

Satty TL (1980) The analytic hierarchy process. McGraw-Hill, New York

Satty TL (1994) Fundamentals of decision making and priority theory with the analytic hierarchy process. RWS Publications, Pittsburgh

Singh H, Kumar R (2014). Selection of chain-material in automobile sector using multi attribute decision making approach. Paper presented at the annual meeting of the ISAHP. Grand Hyatt Hotel, Washington, D.C

Singh J, Singh H (2014) Performance enhancement of manufacturing unit using Six Sigma DMAIC approach: a case study. In: Proceedings of the international conference on research and innovations in mechanical engineering. Springer

Snee RD, Hoerl RW (2003) Leading Six Sigma: a step-by-step guide based on experience with GE and other Six Sigma companies. FT Press, Upper Saddle River

Snee R, Hoerl R (2004) Six Sigma beyond the factory floor: deployment strategies for financial services, health care, and the rest of the real economy. PH Professional Business

Tahriri F, Mousavi M et al (2014) The application of fuzzy Delphi and fuzzy inference system in supplier ranking and selection. J Ind Eng Int 10(3):1-16

Tilo P, Wolf $\mathrm{R}$ et al (2004) Integrating six sigma with quality management systems. The TQM Magazine 16(4):241-249

Tiwary A, Pradhan B et al. (2014) Application of multi-criteria decision making methods for selection of micro-EDM process parameters. Adv Manuf 2:251-258 
Tönshoff HK, Reinsch S et al (2007) Soft-computing algorithms as a tool for the planning of cyclically interlinked production lines. Prod Eng Res Devel 1(4):389-394

Vats G, Vaish R (2013) Selection of lead-free piezoelectric ceramics. Int J Appl Ceram Technol 11(5):883-893

Vats G, Vaish R (2014a) Phase change materials selection for latent heat thermal energy storage systems (LHTESS): an industrial engineering initiative towards materials science. Adv Sci Focus 2(2):140-147

Vats G, Vaish R (2014b) Selection of optimal sintering temperature of $\mathrm{K}<\mathrm{sub}>0.5</ \mathrm{sub}>\mathrm{Na}<\mathrm{sub}>0.5</ \mathrm{sub}>\mathrm{NbO}<\mathrm{sub}>3$ $</$ sub $>$ ceramics for electromechanical applications. J Asian Ceram Soc 2(1):5-10
Wang Y-M, Elhag TMS (2006) Fuzzy TOPSIS method based on alpha level sets with an application to bridge risk assessment. Expert Syst Appl 31(2):309-319

Wei C-C, Liang G-S et al (2007) A comprehensive supply chain management project selection framework under fuzzy environment. Int J Proj Manag 25(6):627-636

Yoon KP, Hwang C-L (1995) Multiple attribute decision making: an introduction. Sage Publications, Beverley Hills

Zadeh LA (1975) The concept of a linguistic variable and its application to approximate reasoning-I. Inf Sci 8(3):199-249

$\mathrm{Zu} \mathrm{X}$, Fredendall LD et al (2008) The evolving theory of quality management: the role of Six Sigma. J Oper Manag 26(5):630-650 